permission to include some of their cases, and also Dr. Jayanti Chakravorty for her help.

Binoy G. Chakravorty,* PH.D., M.B., M.S., F.R.C.S., F.R.C.S.ED.,

Senior Neurosurgical Registrar, Royal Victoria Hospital, Belfast.

Colin A. Gleadhill, M.D., F.R.C.S.ed., Neurological Surgeon, Royal Victoria Hospital, Belfast.

* Present address: Institute of Postgraduate Medical Education and Research, S.S.K.M. Hospital, University of Calcutta.

\section{Fatal Case of Toxic Erythema after Chlorpropamide (Diabinese)}

Brit. med. F., 1966, 1, 148

Chlorpropamide is widely used for the control of late onset nonketotic diabetes mellitus, and is classed as an arylsulphonylurea. Among its many side-effects are blood dyscrasias, which include thrombocytopenia (Fitzpatrick, 1963), leucopenia, low-grade anaemia, eosinophilia (Rothfeld et al., 1960), aplastic anaemia (Erslev, 1964), and agranulocytosis (Stein, 1964). Transient gastro-intestinal disturbances, intolerance of alcohol, hypoglycaemia (sometimes prolonged), impairment of liver function (Rothfeld et al., 1960), foetal damage (Campbell, 1963), and neuropathy have been reported.

Purely dermatological toxicity often shows itself as an erythematous rash of varying severity which disappears on withdrawal of the drug. Photosensitivity (Hitselberger and Fosnaugh, 1962), erythema nodosum, erythema multiforme (Stewart et al., 1959), and the Stevens-Johnson syndrome (Yaffee, 1960) have occurred, but hitherto no fatal reaction has been reported in the literature. These skin manifestations are paralleled closely by those due to the sulphonamides, and the fatal effects of some long-acting preparations have recently been reviewed in these columns (B.M.F., 1964).

\section{CASE Report}

A lady of 71 consulted her doctor about a scaly rash on her knees and excessive thirst. Psoriasis and diabetes mellitus were diagnosed and Diabinese (chlorpropamide) prescribed, $250 \mathrm{mg}$. twice daily being given for three days, then increased to $500 \mathrm{mg}$. twice daily for two days, and lowered to $250 \mathrm{mg}$. twice daily as glycosuria was controlled. A few days later she developed an extensive purplish skin eruption, while mouth lesions rendered swallowing painful. The drug was withdrawn on the third day of this reaction and antihistamine given.

She was admitted to hospital on the tenth day of the rash, and examination showed perhaps $85 \%$ of the skin involved by purpuric lesions, some of which could be recognized as target-like. Marked crusting was present on her face and lips, there was severe conjunctivitis and chemosis, and the oral mucosae were denuded. Large intact bullae were present on the feet and ankles. Her blood-pressure was $150 / 70 \mathrm{~mm}$. $\mathrm{Hg}$, and no abnormality was found in the heart, lungs, or abdomen. Though a diagnosis of severe drug eruption was made at this time, her general condition gave no cause for alarm. Plasma electrolytes, alkali reserve, and urea were normal, while the blood sugar was $296 \mathrm{mg} . / 100 \mathrm{ml}$. A radiograph of the chest showed slight cardiac enlargement, a clean sample of urine revealed 20 leucocytes per high-power field, and culture yielded a moderate growth of Staph. pyogenes. Her white cell count was 5,000, and E.S.R. was $27 \mathrm{~mm}$./hour.

However, after a further $\mathbf{4 8}$ hours her condition deteriorated, the eruption had become more extensive, and a staphylococcus was

\section{REPERENCES}

Chambers, W. R., Harper, B. F., jun., and Simpson, J. R. (1954). F. Amer. med. Ass., 155, 358.

Eck, H. (1957). Münch. med. Wschr., 99, 1070.

Forbus, W. D. (1930). Bull. Fohns Hopk. Hosp., 47, 239.

Jokl, E., and Wolffe, J. B. (1954). Acta Genet. med. (Roma), 3, 245.

Krayenbühl, H., and Yasargil, M. G. (1958). Das Hirnaneurysma. Geigy, Basle.

O’Brien, J. G. (1942). Brit. med. F., 1, 607.

Ross, R. T. (1959). Canad. med. Ass. 7., 81, 477.

Ullrich, D. P., and Sugar, O. (1960). Neurology (Minneap.), 10, 288. isolated from the mouth and conjunctivae which was sensitive to a wide range of antibiotics, though untypable by phages. Her blood sugar rose to $520 \mathrm{mg} . / 100 \mathrm{ml}$. and urine became strongly positive for ketones. Treatment with soluble insulin controlled this moderate ketosis, but she remained very ill and died suddenly despite intramuscular hydrocortisone and soluble penicillin.

At necropsy almost the entire epidermis was found to be peeling off, more large bullae having formed terminally. The histopathology showed gross dilatation of the dermal blood-vessels and oedema, while the epidermis showed clefting due to spongiosis. No true acantholysis was demonstrated. Some bile-stained fluid was found in the trachea and main bronchi, while terminal lower lobe bronchi showed hypostatic congestion and oedema. There were irregular areas of greyish translucent appearance visible throughout the pancreas. The liver showed only foci of fatty change. Bladder and ureters were normal and the arteries were almost entirely free of atheroma.

\section{COMMENT}

The skin lesions of this case were similar to those described by Rothfeld et al. (1960), whose patient fortunately recovered despite hepatic damage. The eruption was basically an erythema multiforme with severe mucosal involvement. The fatality rate in erythema multiforme, even the severe variety (Stevens-Johnson syndrome), is only variably related to the extent of the skin lesions, while necropsy fails to reveal the immediate cause of death in many cases. Furthermore, a severe biochemical dyscrasia was excluded in the present case. Her ketotic exacerbation of diabetes mellitus was attributed to widespread skin sepsis, though there may have been a minimal urinary infection.

That this clinical picture resulted from Diabinese (chlorpropamide) is most probable, judging from the time relationship and from the fact that similar but less severe cases have been described before. Neverthless, pure coincidence is remotely possible.

I would like to thank Dr. I. B. Sneddon for permission to publish this case and for his helpful advice on its preparation.

\section{GeOfFrey L. TUlLETT, B.SC., M.B., M.R.C.P., D.P.M., Senior Registrar in Dermatology, Rupert Hallam Institute, Sheffield Royal Infirmary.}

\section{REFERENCES}

Brit. med. F., 1964, 2, 1410

Campbell, G. D. (1963). Brit. med. 7., 1, 59.

Erslev, A J. (1964). F. Amer. med. Ass., 188, 531.

Fitzpatrick, W. J. (1963). Diabetes, 12, 457.

Hitselberger, J. F., and Fosnaugh, R. P. (1962). F. Amer. med. Ass., 180,

Rothfeld, E. L., Goldman, J., Goldberg, H. H., and Einhorn, S. (1960). Ibid.. 172, 54

Stein, J. H., Hamilton, H. E., and Sheets, R. F. (1964). Arch. intern. Med., 113, 186. Stewart, R. C. Piazza, E. U., Hyman, H., and Harwitz, D. (1959). New

Yaffee, H. S. (1960). Arch. Derm., 82, 636. 